\title{
Kandyan Elitism as an Eastern Brand of Elitism and Formulating Kandyan Elite Domestic Architecture
}

\author{
Nishan Rasanga Wijetunge
}

\begin{abstract}
This paper attempts to discern the condition of elitism with relation to a unique Eastern situation - the indigenously-governed Kandyan regions of Ceylon - that only saw light of the relentless forces of Western-led globalization as late as 1815. Kandyan elitism, over the years, has been either misinterpreted or addressed facilely by scholars, while being indifferent to the separation between Kandyan elites and sub-elites. The objective here is to make explicit the factors underlying this division, which could be manifested through Kandyan elite and sub-elite domestic architectures. Identifying ambivalences evident in the two types is intrinsic to this exercise.
\end{abstract}

\section{Capitalism and Western Elitism}

The perception of intellectual superiority of the Western world over its Eastern counterpart has persisted for centuries, and reached a point of culmination by the 19th century; through Western-instigated colonial projects. The foundation to this hegemony was laid during the Renaissance in 15th century Europe, perceived to be a quantum leap experienced by the ever-prevailing process of globalization. Even prior to the spawning of so-called "modern-era" itself, as Said (2003: 31-92) postulates, Western epistemological pre-eminence had been largely propagated by their prolific texts. As a direct consequence of Western coIonialism, the colonists placed themselves at an immutable position as the controlling-core of the world, while relegating the colonized to a subordinate periphery (Perera, 1994: 211). Henceforth, Western knowledge became the accepted norm while ancient Eastern epistemological realm was pushed to an oblivious corner. In such a milieu, the Western academia has not only devised a fervent body of knowledge on the discourse of "elitism" over the epochs, this knowledge has been inculcated throughout the world. Therefore, the widely-received canon of global-elitism applied to wide-ranging contemporary and historical situations is really, the Western structure of elitism superimposed on non-Western conditions. This structure has hence been blindly and ignorantly appropriated by Eastern scholars, and applied to Eastern contexts, undermining the opportunity to envisage the ensemble of quintessential factors that constitute elitism in the Eastern sense.

On the other hand, albeit laudable epistemological and scientific instigations of pioneering dimensions in the Ancient Far-East, it has to be categorically acknowledged that science and technology culminated to its present sophisticated state in Europe, with the spawning of the so-called Modernity. Renaissance, religious reformations, enlightenment and industrial revolution - all conceived to be quantum leaps in the relentless process of globalization - were affected following the15th century, when Europeans made a conspicuous change from communality (based on orthodox Christianity), into to ego-centric individualism, which largely relegated religion (de Silva, 2003). The mammoth shifts these developments spawned, proved too radical for the feudal economic system as well culture as a whole, in the Western world at the time. Consequently, a capitalist socio-economic structure which was more apt for such development was appropriated, which in turn assured the consolidation and posterity of Western science and epistemology.

With the growth of Western science, knowledge and awareness of the environment also grew, as conceiving the great mysteries of what was 'Created by god, the all mightily' was conceived as one of science's vital tasks. However it is widely postulated that, although Western science has experienced a metamorphosis through the epochs of archaic primitivism and paganism - which perceived different aspects of nature to possess supernatural powers - there is still a long way ahead. De Silva (2006: 11-15) and Steger (2003) postulate that capitalism, which is inherently based on the exploitation of labour, not only paved the way for scientific consolidation historically, it has also misinterpreted the definition for development, and facilitated a rigorous process of exploitation. Exploitation of fellow human beings as well as of the environment was exacerbated to hitherto unforeseen levels through the ever-expanding capitalist practices. Capitalism which is driven by profit-making as Mandel (1982) tells us, since its advent, has not only manufactured what people essentially need in order to survive in the world, it has further prompted them to strive for, and acquire, the not-so-essential amenities to life; instigating what 
is widely propagated as a consumer-society. All such developments according to de Silva (2006), sprung up in 15th Century Europe, which was consequently proliferated the world over through European colonialism. The simple logic is that the world possesses only limited resources, not sufficient for everyone to live lives of consumerism. This was true in deed in the 15th century, when European consumer societies decided to resort to unjust and exploitative means of colonialism in order to achieve their capitalist realities, and in the contemporary world, such practices are still continued via neo-colonialism (Perera, 1994: 328371). Furthermore, the destruction of the environment was brought to unprecedented levels during the 18th century-initiated process of industrialization in Western Europe, and has been continuously sustained to the present-day levels of catastrophe. Western elitism of the Modern era - the brand of elitism discerned and propagated the world over by Western academia was born and nourished in such a capitalist and egocentric realm.

\section{Concepts of Western Elitism}

Rousseau (in Bottomore, 1993: 101), based on the world-renowned Politics of Aristotle (Which reads, "From the hours of their birth some are marked out for subjection and some for command"), instigates the apparent basic differences among human beings, which he has credibly classified and transcended to levels of inequalities. "...there are two kinds of inequality among human species; one, which I call natural or physical, because it is established by nature, and consists in a difference of age, health, bodily strength, and the qualities of the mind or of the soul: and another, which may be called moral or political inequality, because it depends upon a kind of convention, and is established, or at least authorized, by the consent of men. This latter consists of the different privileges, which some men enjoy to the prejudice of others; such as that of being more rich, more honored, more powerful or even in a position to exact obedience" (Bottomore, 1993: 102).

Hence, one could assume that Elitism was derived out of such pioneering Western notions of human inequalities, prevalent over the ages, and has been discussed in more general or wide-ranging terms in recent times. The rationalization with relation to various conspicuous periods of recent history derived by Bottomore, after having referred to various wellestablished scholarly propagations reads, "The word 'elite' was used in the seventeenth century to describe commodities of particular excellence; and the usage was later extended to refer to superior social groups, such as prestigious military units or the higher ranks of the nobility" (Bottomore, 1993: 1). ${ }^{1}$

Conversely, Horton's point of view establishes the role of elitism after the Industrial Revolution taking place in Western Europe throughout the 19th century. Prior to this juncture, European-elite largely consisted of the higher clergy as well as the land-owning nobility, and always had been an inheritable status. "Membership of an elite group is often inherited, but in some societies it may be acquired" (Horton: 1964, 294). ${ }^{2}$ This inclination proliferated throughout the world by the means of colonialism. Appropriating from this background, Barber (1968: 19, 22), utilizing the simplicity of ranking dimensions, delineated three separate but interrelated dimensions for the elite; the economic dimensions, the power dimensions and the evaluation or prestige dimensions. Both Vilfredo Pareto and Garento Mosca are two laudable proponents of the discourse, to define Western Elitism in more relevant terms as Bottomore $(1993,1-12)$ points out. Their inculcations could be condensed into a few common concepts that can be logically applied to Western elitism within the entire modern era. In every society (Western societies in the core and their subordinate counterparts in the peripheral world), the elites could either be found in the form of various 'functional groups' or as a 'political class'. The more conspicuous and loosely-defined latter consist of those who occupy the posts of political command and, more vaguely, those who can directly influence political decisions. ${ }^{3}$ Within the political class itself, there exists a smaller group, the 'political elite' or 'governing elite'; consisting of the individuals who actually exercise political powers in a society, at a given time. This includes members of the government, and of the high administration, military leaders, and in some cases, politically influential families of an aristocracy or royal house, and leaders of powerful economic enterprises. However, it is less convenient to set the boundaries for the 'political class' as it might include the 'political elite' as well as the 'counter-elites'. The latter may comprise of leaders of political parties which are out of office and representatives of new social interests or classes such as trade union leaders, groups of businessmen and intellectuals who are active in politics. The political class hence, as suggested by Bottomore (1993: 8), comprises a number of groups, which may be engaged in varying degree of cooperation, competition or conflict with one another. Henceforth, in Western conception, the governing elites, formidable in both political and economic spheres, are the most powerful, while they allow certain functional elites to prevail in close coalition; to safeguard the system and means that sustain them as elites. At the end, it all comes down to the conduct of a minority that relegates the majority, prompted by relentless greed, triggered through the modern-era capitalism.

\section{Kandyan Kingdom: A discrete existence}

Iberian-Portugal from 1498, gradually composed a vast seaborne Empire in the form of loosely-knit military and trading outposts over the Indian Ocean region, and formed Lisbon as their hierarchical centre. This act could be perceived as the stepping stone of the attempts by the capitalist Western-world, to pur- 
sue their ego-centric future fulfillments. This could furthermore, be envisaged as the pioneering instigation of Euro-centrism, that was brought to a point of culmination by the 19th century.

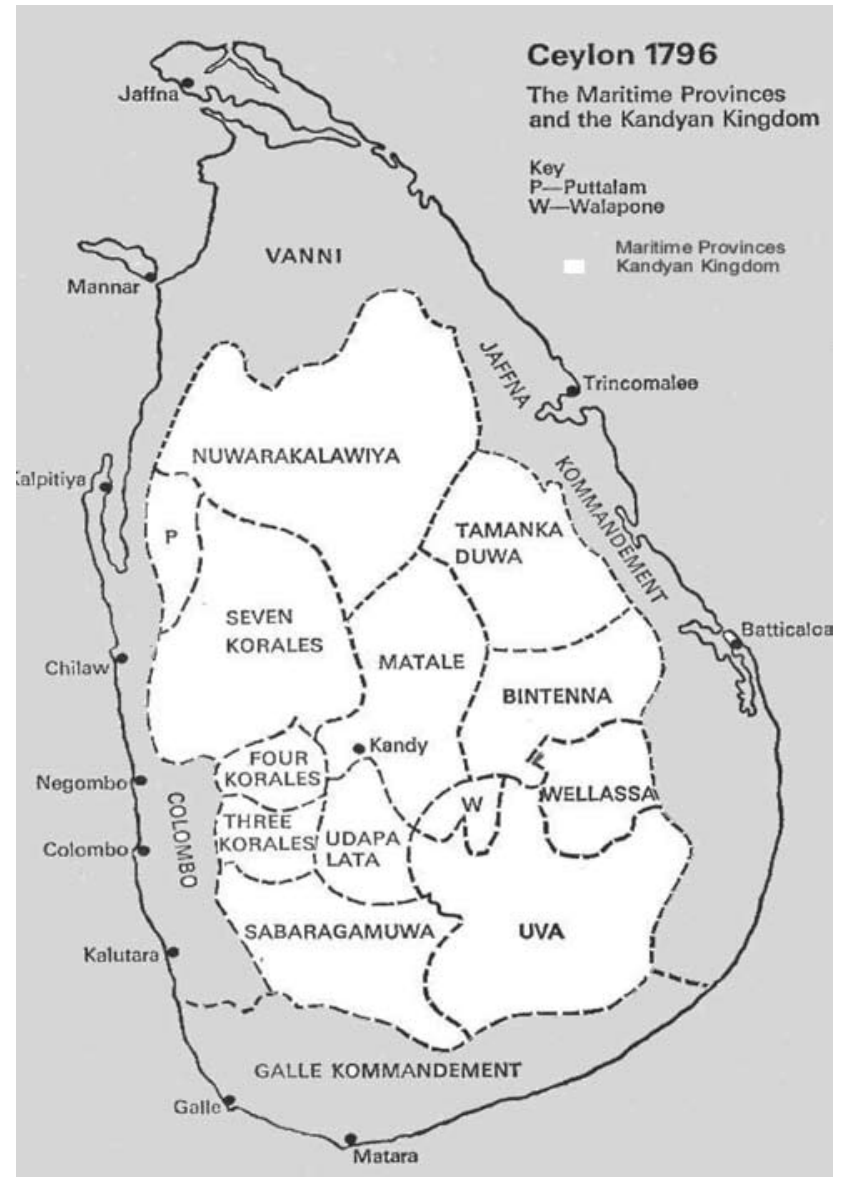

Figure 1: Map showing the land-locked status of Kandyan regions by 1796

Source: Mills, 1964

The Portuguese who had been controlling maritime Ceylon since 1505 were superseded by Dutch - a Western European capitalist force - that had consolidated to the Eastern colonial forefront by the mid 17th century. Although the Dutch V.O.C (The East India Company) managed to completely oust Portuguese from Ceylon to acquire their territories, they failed miserably to penetrate the interior. This was owing to the persisting resistance of the Kandyan Kingdom, located in the hostile geographic region of central hillcountry. This Kingdom had been originally formed as Senkadagalapura during the reign of Vikramabahu III of Gampola in the mid 14th Century, and later was formed as a revolt-territory that resisted Maritime Portuguese rule by King WimaladharmasooriyaI in 1590. King Rajasinghe II, a latter ruler of the Kingdom, signed a treaty with the Dutch and collaborated to successfully annihilate the Portuguese from maritime Ceylon by 1658 (de Silva, 1981: 133134). ${ }^{4}$ This treaty however, was circumvented by the shrewd Dutch administration later on, as they feared it favored Kandyans more. Consequently, the abhorrence between the two parties eventually led to war, and hostilities prevailed in the form of occasional as- sault on one another, for decades. However, toward the closing years of Dutch occupation in Ceylon (by 1796), the Kandyans had lost all their maritime possessions to the V.O.C, and were land-locked in the central hill-country itself (Pakeman, 1970: 68-69), leading to unprecedented austerity after centuries. ${ }^{5}$ The last time that a Sinhalese monarchy may have faced such a condition was probably before the 15th century, during Dravidian invasions from Southern India. The following written testament by a soldier of the British army (that took over the maritime regions from the Dutch in 1796), writing in 1803 (in perera, 1994: $147)$, articulates the solitary position of the Kingdom. "I have often heard persons, unacquainted with the interior of Ceylon, express their surprise that a tract of land in the heart of the island, cut off from all external supplies, and everywhere surrounded by European settlements, should so long have remained in the hands of a people neither strong nor warlike, in spite of repeated efforts to wrest it from them". James Cordiner (1807:103), a Britisher who visited the kingdom shortly afterwards, best-describes in his descriptive writings, its modestly-globalized position. However, in 1796, at the point where British acquired Dutch-held maritime regions, Kandyan kingdom still possessed the bulk of island's land mass, which had been subdivided into twenty one grand divisions.

\section{Deriving Kandyan Elitism}

\section{Historical making of stable structures}

In medieval Ceylon, Elitism was essentially a factor that had been empowered by feudalism, which in turn was backed by the primordial caste-system. Ceylon had originally received the fourfold Indian caste system with the waves of immigrations that occurred predominantly from Western, Eastern and South-Eastern parts of India, as far as the 9th century B.C; with the most documented affair taking place in the 5th century B.C., as the arrival of prince Vijaya of the Sinha (Lion) tribe, along with a contingent of five hundred (de Silva, 2008). With the advent during Anuradhapura period in the 3rd century B.C., of the philosophical doctrine of Buddhism that subverts the concept of caste, Sinhalese consequently developed their unique equivalent to the Indian caste system. The royal family, essentially of warrior (Kshatriya) origin (always directly traceable to Northern Indian Aryan Royal bloodlines), and aristocrats (close relatives of king who were made highest officials of the Kingdom), made the uppermost echelons of the Anuradhapura period, while the majority of the populace was engaged in paddy cultivation as their main means of livelihood. Even the artisans that immigrated with prince Vijaya, and the ones to have done afterwards, were placed at the same level in the social strata as the farmers. Documented evidence such as Mahavamsa - the comprehensive and continuous historical inscription from the 2nd Ct. B.C., of the Buddhist monastery of Maha Vihara of Anuradhapura - makes references to 
the feeble class distinction between aristocrats and masses in the historic city, in periods of great prosperity which saw the culmination of Buddhism. The strong social and economic structures that ensued during the Anuradhapura period perpetuated for one and half millennia, until Southern Indian invasions prompted the Sinhalese seat of power to shift via PolIonnaruwa, Dambadeniya, Yapahuwa, Gampola, Kurunegala and Kotte respectively, until Kandy became the concluding destination. Schumpeter's propagation that, "Social structures, types and attitudes are coins that do not readily melt. Once they are formed they persist, possibly for centuries...," (Shumpeter, 1942: $12-13)^{6}$, which indeed, is affirmative with relation to ancient Ceylon. The essence (the basic structure) of strong social and economic systems that developed during Anuradhapura was sustained down into the Kandyan period; having survived continuous South Indian and European interventions for nearly a millennium. However, the overwhelming South Indian fervor that has always persisted in the backdrop (owing to cultural and trading ties) penetrated this structure, and revived to a substantial extent, the once-subverted caste system, by the time of forming of the Kandyan Kingdom. Socioeconomic and administrative structures of the Kingdom have been addressed by numerous Westerners who manage to visit it during the course of 18th and 19th centuries. Despite the apparent contiguity to Said's Orientalism (2003), their well-documented affairs best manifest the socio-cultural, economic and administrative structures as well as architectural practices of the Kandyan provinces before 1796, and concretize the ever-existing cultural clash between West and the East.

\section{Social structure}

When the kingdom of Kandy was enjoying a spell of economic and military successes in the mid 17th century, its political, economic and administrative structures were also at their heights. In Kandyan social structure, the cultivator caste (majority) was second only to the Royal caste, to which the King and his immediate family circle belonged. The cultivators, referred to as 'Govigamas' that relegated all service casts to the peripheries of society, was then divided into 'Radala' (chiefs), 'Sitanos' (nobles) and ordinary peasants (Perera, 1991:57). ${ }^{7}$ The Royal caste still had genealogical Kshatriya (warrior) origins in the subcontinent, while the majority of numerous service castes (of specialist and ritual services) could be traced back to Southern India; Malabar and Coromandel coasts in particular (Roberts, 1982:1). A faction of cultivators was given high administrative and social positions by King in addition to close relatives of his, while some were appointed as petty officials. It was these highest ranks of administrative and social nature that made Govigamas either Radalas or Sitanos respectively. The Kandyan caste system, analogous to counterparts found in neighboring India, led to very unique social and administrative structures of its own. It is pertinent to mention that Kandyan Kingdom, as a landlocked and oblivious entity, the only apparent alien influences it received was possibly from the Southern Indian states, South-East Asia, as well as of the Muslim traders (mainly from Southern India [originally from the Middle East], and also South-east Asia) who freely moved from the coast to the interiors. Conversely, the maritime regions were experiencing a rigorous level of globalization in comparison; owing to colonial practices.

\section{Administrative \& economic structures}

With relation to administrative structure, king was considered the supreme ruler of the kingdom who had to assure the protection of Sinhalese culture and the state religion of Buddhism. Hence, the appropriation of Lord Buddha's tooth relic symbolized the patronage of the Sangha (the Buddhist order) towards the monarchy, and its acceptance by the populace; both factors vital for the affirmation of legitimacy. Under the king, the administrative structure contained the first Adigar (the prime minister) and also other Adigars (mainly two Chief ministers or Maha Adigars and a 3rd Adigar who was also termed Maha Nilame) exercising great power and influence. They were the principal ministers and the high judiciary of the kingdom (Madugalle, 2005: 28). As Perera elaborates (1991: 47-48), out of the twenty one Kandyan grand divisions, nine smaller provinces (Districs) of the Kingdom's interior were termed 'Rata's, and administered by Rate Mahattayas, while twelve of the more extensive regions that surrounded Ratas, were referred to as 'Disas' or 'Disavanes', administered by Disavas or provincial governors. Although de Silva (2010) suggests that both positions were parallel in the hierarchy, Madugalle (2005) seems to think otherwise. The former also tells us that Muhandirams were appointed as heads of various departments in the King's court and shared more or less the same privileges as Disavas and Rate Mahattayas. On the other hand, there were officials of the palace establishment, revenue administration and chief temple authorities known as 'Nilames' (Madugalle, 2005: 26-31), who were also influential in the Kingdom's affairs. By drawing an analogy with the Western-derived elite structure mentioned at the beginning of the paper, all these positions in Kandyan administrative hierarchy could be discerned as 'political' or the 'governing' elite.

Under Disavas and Rate Mahattayas, were minor officials such as Koralas (in charge of fairly large areas of Korales, consisting of a number of villages), Vidanes (in charge of cultivation and tax collection of a number of villages), and finally, Arachchis (the protectors of the village or traditional village chiefs). Vidanes were in charge of various service cadres belonging to a number of service castes while Arachchis were responsible for each service caste. Apart from such positions, there were Maha Mohottalas and Mohottalas; free-yeomen with their very own land which they 
cultivated exempt from taxes payable to King's treasury. As De Silva (2010) tells us, at times, they were made Muhandirams. Furthermore, according to Madugalle (2005: 29), they were also given lower ranks of district administration to be titles as Disawe Mohottalas of certain Disawanes. De Silva (2010) also states that a step above the ordinary cultivator caste peasant was the 'Ralas', who were relatively wealthy and respectable. They are not to be mistaken with the ones to share the same titular name who held certain minor positions as lower district administrations (as Rate Ralas) or in the royal palace establishment (as Talpath Wadana Rala, Muthukuda Rala etc.), as Madugalle points out (2005: 26-33). Rate Adikarams were also a faction who held provincial judiciary positions. On the other hand, various secretary positions in the palace establishment, chief, commander, captain positions in the military establishments and chiefs (assistants) positions of district offices were given the name 'Lekam'. It has to be noted here that all these were minor positions in the Kandyan administrative hierarchy. In this pre-modern context, a single group of people in power controlled the Kingdom's socioeconomic aspects as a homogeneous political entity. As they were not rivaled or threatened by alternative groups with political ambitions - holding oppositional social and economic influences - the concept of the 'political class' can not be applied here.

In the eyes of certain Westerners such as Cave (1894: 53-54), such a structure facilitated "...the worst excesses of unscrupulous tyrants..." to flourish over masses, operating on "harsh laws of the Sinhalese kings".

The administrative machinery functioned on a primordial land tenure system referred to as 'Raja Kariya', All the officials of high and low ranks as well as the cultivator caste peasants were provided with portions of land to make their livelihoods from paddy cultivation as the "staple food of the people" as John Davy (1969: 207), a British ambassador to the late 18th century Kandyan court wrote. The sizes of these land allocations were proportional to administrative ranks. The peasants worked these lands and also the ones of their respective lords' while ".....a fixed share of their produce had to be yielded to their feudal overlord- generally a land owning chieftain or a Buddhist monastery" (Pakeman, 1970: 127). If this is to be further-elaborated, the power over whole of Kandyan territory's land was vested in the king, and its ownership was efficiently distributed as an ensemble of villages of varying sizes. Gabadagam- villages to supply all requirements of the palace, Viharagam- villages dedicated to Buddhist temples and monasteries, Devalagam- Villages belonging to temples dedicated to various deities, Nindagam- villages which were the property of granters or temporary chiefs, and finally, Vidanagam- Villages under the petty administrative position of Vidanes (Perera, 1991: 50). Hence, a periodic tax referred to as the 'Agrabhagaya' (the good portion), as De Silva (2010) tells us, was accumulated from all villages except for the first two categories, to be granted to the Royal treasury. The service castes provided their essential services as artisans in the self-sufficient Kandyan regions and were also allocated lands to live on and cultivate. The artisans lived as communities in villages and specialized in the manufacturing of different goods and services. They were allowed to trade their produce to obtain foodstuffs to make their living. The communities in villages belonging to temples were given sufficient rations for the ritual services that they rendered. Such communities according to Roberts (1995), engaged in agriculture as a parallel means of livelihood. The Adigars in most occasions were genealogically connected to the Royal family while other high administrative positions of Disaves, Rate Mahattayas, Muhandirams, Nilames etc. were given to certain Radala groups within the cultivator caste. In relation to the Kandyan system, all such positions that had direct access to political and economic means, which allows the exercising of substantial levels of social influence, could hence be conceived as Kandyan elites; in the Western sense. All positions below these ranks, yet above the one of cultivator peasants - making the liaison between the two groups - rationally become sub-elites or the 'middle class' (in contemporary terms).

\section{A brief comparison}

However, the most pertinent factor in relation to Kandyan economic frame work is that, taxation was never a rigid practice. De Silva (2010) affirms, "it was never clearly laid-down", and predominantly depended on the nature of harvest as well as the prevailing economic conditions. It was merely a means to sustain a political and economic system, which was formed and delimited by a culture, which was essentially molded on two conspicuous Eastern religions (mainly Buddhism and vestiges of Hinduism). The production sectors of agriculture and manufacturing of goods were never meant to form surplus values but subsistent levels. Although the system superfluously appears to be facile and unjust - as it forced people to remain within their marginalized castes, and allowed certain privileges to the governing elites who seemingly exploited them - it was more or less static in the long run. Henceforth, it shared no underlying similarities with European modernity dictated by capitalism, which always strives on exploitative growth. The Westerners hence discerned Kandyan structures to possess no potential for "further exertion" and confirmed it to be an existence of "easy apathy" (Cordiner, 1807: 105). However, such Western inculcations could be questioned in light of Michel Foucault. He postulates that, in the "panoptic" modern-age (which is the culmination of European-instigated Modernity), the "great confinement" has contained the society through relentless categorization (see Jose: 1998). The origin of systematic categorizations in fact, could be traced back to the 19th century, where colonialism was at 
its helm. Conversely, situations analogous to the 18th century Kandy examined here existed throughout the pre-modern world, where people were only subjected to intermittent suppression. However, the level of human suppression has been gradually exacerbated in the name of Modernity over the years. Consequently, by contemporary times, individuals have been directly brought under the "eye of power".

\section{Possible influences on Kandyan Architecture}

By the late 18th century, the building traditions of Kandy, as an intrinsic traditional element of its unique culture, had evolved to a particular state to manifest a unique identity. However, it is pertinent to consider the fact that, by this time, Singhalese architecture in the Kandyan regions had been exposed various outside influences (Lewcock et al., 2002: 20); affirming the primordial nature of globalization. Kandy (Kande in Sinhalese giving the meaning of mountain) was formed as a kingdom during the Portuguese-era as a independent state which opposed Portuguese colonial rule, by a monarchy that fled from Portuguese-held Kotte (in the maritime regions near present day capitol Colombo). Hence, possible architectural influence that they may have carried with them to Kandy from the Portuguese-maritime cannot be negated. The Dutch who gradually took-over from the Portuguese had good diplomatic and trading relations with Kandyan monarchy for decades, before relations deteriorated towards the end of the 18th century. For a certain period, the Dutch acknowledged their subordinate status to the Kandyan king, for example, by facilitating an array of diplomatic missions ranging from offering their services to Kandyan religious missions to South East-Asia to paying of annual stipends of gratitude etc. Owing to these relations, the influence of Dutch architecture that was well-established in the maritime, on its Kandyan counterpart is rationally inevitable. On the other hand, Muslims who had engaged in trading activities for centuries in Ceylon may be another factor of possible influence on Kandyan architecture. They were blockaded after the Portuguese seized the island's coastal line and were consequently compensated by the Kandyan King Senarath I by settling them down (mainly in the Eastern regions of the country) as well as allowing them to conduct commercial activities with Kandyan regions. However, the bulk of such alien influences were directly dealt with by the Kandyan state itself, and not by the masses. Hence, the possible alien architectural traditions to have appropriated could be deductively attributed to Kandyan grand design tradition; culturally delimited to Royal and religious edifices. The incongruous factor about Kandyan Kingdom was that the buildings of even its elites and sub-elites were put in contiguity to those of the masses via employing vernacular tradition. Yet, the masses were further-relegated to primitive vernacular forms whilst the elite and sub-elite, especially the former, were allowed by the King himself, to appropriate certain elements of the jealously-guarded
Kandyan grand design tradition. ${ }^{8}$ Henceforth, even a trickle-down effect of grand design traditions to the non-elite masses through emulation was annihilated. From an ensemble of evidence adduced from Western European situations such as Britain and France in the modern era, where the aristocrats and bourgeoisie (elites and sub-elites of society) as well as the Royals were franchised to utilize grand design tradition at their free will as Evans (1993: 55-91) illustrates, the medieval Kandyan situation is a clear contrast. The flexibility of the Western situation could be postulated to capitalist and egoistic thinking that has overshadowed Western cultures for half a millennium. The geocentricism spawned in the Modern-era West will be elaborated later in the paper.

Moreover, the Kingdom from its humble beginnings had always maintained cultural and commercial ties with the Southern Indian states that did not diminish even after becoming landlocked. Although scholarly speculations concurrently prevail, and valid analogies between cultural and high cultural architectural ties of Kandy and the Southern Indian states (Kerala in particular) have been drawn in the Sri Lankan architectural rhetoric, this has never been sufficiently looked into. However, the close relations that existed between the Kandyan royal blood lines and also of the aristocracy with Southern India provide backing to such speculations.

\section{Factors Determining the House Form}

Rapoport (1969) adduces valid examples from around the globe, from different periods in human history, to affirm culture to be the foremost factor in molding the built form, while all other alternative factors, especially the environment, becomes secondary. His canon could be logically attributed as being ideologicallyneutral (as it does not advocate merely a Western point of view on the discourse), as the sited examples not only come from the Western world, but also from all over the East and elsewhere. With relation to the Kandyan situation, with the absence of other possible alternative determiners affecting the built form such as economy, defense etc., the second most conspicuous factor could be envisaged as its climate. Why such factors did not become seminal determiners will be addressed later on.

\section{Cultural Factors}

\section{Beliefs}

A clear analogy could be drawn between Kandyan built form and Rapoport's propagation, as it is culture in general terms, was predominantly based on the philosophical doctrine of Buddhism as well as for other sets of believes more closely associated to ever-present influence of Hinduism. These beliefs were carried down from generation to generation through tradition, and varied from one cultural group to an- 
other. As Nimal De Silva validly postulates, "The traditional house that has existed in Sri Lanka for more than two thousand years was an outcome of a strong philosophy of Buddhistic life - i.e. the simplicity and the impermanent nature of life. The house was part and parcel of nature, the materials were borrowed from the nature and returned to the nature..."

"...The traditional concept was to live in and around the open areas of the house and not within the enclosed compartments of the house and it was the most suitable solution for Sri Lankan climatic conditions.

A house built in this nature, needs regular maintenance and it was continuously embodied in the customs. There are cultural festivals at regular intervals such as New Year, Vesak [celebrated the birth, enlightenment and passing of Lord Buddha], Sudde Poya (Esala) [a full moon day celebrating a certain episode in Buddha's life], etc. The maintenance of the shelter by applying cow dung on the floor and walls, sometimes white washing, thatching the roof, cleaning the house etc., were aimed for the festivals, hence the house was well-maintained" (De Silva, 1990: 16). (Explanations within parenthesis are by the author). On the other hand, the customs and beliefs pertaining to formation of the dwelling were contained in the ancient medieval treatise of 'Mayamatha', which manifests the explicit Indian influence on the discourse. The scientific validity (in terms of Western science) of Mayamatha has been a factor which has been continuously explored by the academia. It overtly laid down beliefs influencing the site selection, design and construction of a house, treating the house metaphorically as a microcosm of the cosmos.

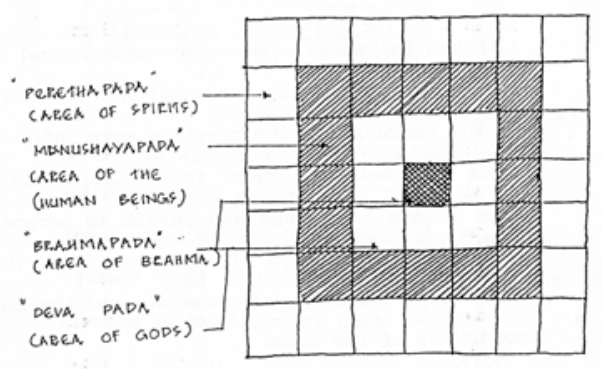

(a) Pertaining to planning of the house chakra" and "Pada-Bedum-Chakra" - diagrams found in Mayamatha - used to achieve a successful outcome. Placing of the main door was a vital task in the design process as it had to be oriented towards the North, South or East as per the "Bhoominage" (the earth serpent) of the site. If the main door was at the head of the Bhoominage- it was to bring death to the chief occupant of the house, if placed at the tail- the wealth of the occupants to be diminished or crops destroyed and if placed on the stomach; prosperity to prevail with wealth, health and better harvest. As per the treatise, forms such as circles, triangles were jettisoned and the ideal forms for the plan were either square or rectangle. Moreover, parts jutting out were perceived to be inauspicious.

The suitable square and rectangular plans were then to be divided into seven vertical and horizontal squares known as "pada". The courtyard of the house was essentially to be placed within the centre square. In terms of building's placement, special measures also had to be taken pertaining to Mayamatha, which compelled the site to be classified into four divisions. The outer-most section was declared as "Perethapada" (area of spirits), the first inner, "Manushayapada" (area of human beings), the second inner, "Devapada" (area of gods) and finally, the innermost centre as "Brahmapada" (area of Brahma). Prethapada and Brahmapada were considered to be unsuitable for locating a building while Manushyapada and devapada were the most ideal. The rules pertaining to construction were mainly centered on the time factor; time to commence work, placing the first foundation stone, placing the main doorway etc. Auspicious times were even applied to planting of vegetation on site. Maya-

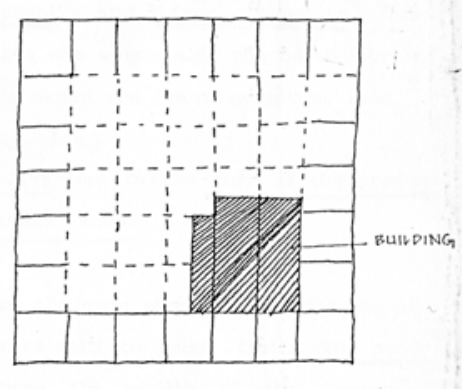

(b) placing building on site

Figure 2: Pada-Bedum-Chakra:

Source: Perera, 1991

With relation to site selection, the features in the site as well as the nature of environment was considered while shape, terrain, existing vegetation, soil conditions, living organisms and its previous uses were absolute determining factors. The soil in particular, was tested for compaction, porosity, color, smell and taste and matched with the clear classifications given in the treatise. In the design process, zoning and orientation was the most vital and referred to as "Bhoomi-nage- matha further laid down guide line for the preparation of timber for construction; for example the distribution and transfer of loads when placing timber members in the roof etc. (Perera, 1991:53). Time for laying the foundation stone was carried out by astrologers to suit the horoscopes of the main occupant and his wife. Enshrinement of auspicious objects was always made as a ritual with blessings of religion as well as gods and deities of belief. These rituals brought in a 
spiritual element to new dwellings, with confidence to the patrons (De Silva, 1990: 16). Such rigorous limitations imposed by religious-imparted cultural beliefs manifests underlying measures taken to safeguard the environment, and efficiently provide users the most ideal environment to dwell in, whenever construction took place. This is completely contrary to the Western position where no such limitations existed; to enable construction activities to take place more freely.

\section{Family life}

Kandyan family life was manipulated by various traditions imposed by a culture that seminally imbued Buddhist philosophies, with occasional modifications caused to it by Hindu influence. Kandyan society was essentially one of male-dominance. With relation to the family structure, men were assumed to be the sole-providers of the family unit, while women were more or less relegated to caring for children and running of the household (Davy, 1969: 207). This cultural norm was valid for the whole of society, irrespective of a family's position in the social hierarchy. The essential characteristic of the traditional Singhalese dwelling found in these parts was their openness, owing to the lack of hierarchical order, and family-life not being overtly separated from visitors. Women of the household eventually slept in one corner of the open verandah of the dwelling, while men in another corner (when there was no clear division of rooms). No special attempts were made to segregate or screen off women from the resident men, and especially from the visiting men who are outside the immediate family circle. When there were rooms, women slept inside while men slept in the open. The concept of privacy in the modern sense was unknown to the Singhalese; in colloquial Singhalese for instance, there is no word which connotes the meaning of privacy. Kandyan life style's element of inter-family relationships was kept to a minimal.

These rather unique characteristics in terms of intrafamily relationships are thought to have derived from Theravada- Buddhist teaching of rejecting the hierarchical structuring in the view of social or family life. Contrary to sub-elite dwellings that manifested the above arrangements, elite dwellings always consisted of multiple rooms, and in some occasions, multiple court yards surrounded by their own sets of rooms (Lewcock et al, 2002: 20-21). This affirms that the Kandyan elite culture was more of a hybrid between Theravada Buddhist and Hindu cultural influences, which eventually manifested itself via elite domestic architecture. The Kandyan royal cultural contiguity to Hindu South India being aped by the elites as well as their very own South Indian origins (the Brahmin genealogy of a majority of Kandyan aristocracy could be traced back to South India) that De Silva (2010) affirms, could have possibly been the causes of this state.
When Buddhism merely influenced the lifestyle promoting austerity and equality without hierarchical order in the dwelling form, the Hindu influence advocated somewhat the contrary. The Kandyan house form, especially of the elites, and sub-elite to a modest extent, hence, was an ambivalent edifice; placed in a liminal state of cultural hybridity.

\section{Climate}

Although Sri Lanka is a small island, it possesses distinct climatic variations, caused by the unique topography, which forms a centrally-located hill-country, surrounded by a flat low country. Consequently, the island could be divided into climatic regions pertaining to the rainfall patterns, and its Central, Western, South-Western parts come under the wet zone, which has a high rainfall and subjected to the South-West monsoon (De Silva, 1990: 17). Kandyan provinces mainly situated in the central parts hence, fall within the wet zone and the mountainous central topography with surrounding thick jungles had constituted it as impenetrable in the eyes of its Western colonizers. Hence, defense was logically omitted from the ensemble of factors that made up the Kandyan built form.

The roof was a conspicuous element in Kandyan climatic condition, which was given due emphasis. Its design with a steep slope provided protection from rain by enabling water to flow off swiftly. The insulation capacity of covering materials and the breathing nature of the roof provided protection from heat. Moreover, the low wall-plate height and long eves protected the walls from the hot sun and rain while cutting down the glare reflected from cloudy skies. The gap between wall and roof provided proper ventilation, and defused light into the room, while the high plinths ensured that the outside breezes entered the houses through fenestrations. The construction materials for walls were always high in insulation capacity. The internal and external verandahs with eaves and small fenestrations of houses kept the hot sun away, keeping the interiors cool and comfortable. The high plinths and impermeable nature of clay used for construction prevented the rising of dampness during rainy days. All materials were accumulated from the locality and simple technology was epitomized to put together edifices which were essentially "low cost" shelters (De Silva, 1990: 16).

\section{Sub-elite and Elite Dwelling}

\section{Sub-elite House: The generic form}

The earliest account of private domestic architecture of the Kandyan regions could be found in the writings of various European diplomats as well as its political prisoners. Robert Knox (in Lewcock et al., 2002: 19), 
an Englishman kept a prisoner who lived amongst the Kandyan Singhalese peasants in the 17th century, writes, "Their houses are small, low, thatched cottages...." he says, "The poorest sort have not above one room in their houses, few above two...". Here, it is rational to perceive that, he is referring to vernacular forms utilized by the masses, pertaining to primordial folk design traditions of the Sinhalese. As John Davy (1969: 161), a British ambassador to Kandy during the late 18th century describes, "Their best houses, those of the chiefs, ... of mud with tiled roofs, raised on a low terrace, and always of a single storey, built in the form of hollow squares; presenting externally a dead wall, and internally bordering the open area is a verandah, with which the side-rooms communicate by narrow doors".

According to Ananda Coomaraswamy (in Lewcock et al., 2002: 20), a typical Singhalese rural house (yeoman's house) was a "simple framed, one-storied, timber and mud walled building with a thatched roof. It contained a square court yard open to sky, surrounded by an internal verandah which was used for all the activities of living and working; off this "the poorest house... had but one room, few more than two or three...."

Although this description tallies with the ones of foreigners made centuries ahead of him, Coomaraswamy's addressing of it as "yeoman's house" is problematic. Perhaps, he may have appropriated the term by making an analogy with the term's connotation in England; a farmer who cultivates his own land, who is a lesser freeholder with political rights below the landed-gentry. However, this analogy makes sense in terms of the Kandyan sub-elite stratum; the free farmers (Maha Mohottala, Mohottala etc.) who may or may not have enjoyed administrative positions. However, his generic house form which he refers to as the 'Singhalese rural house' or the 'Yeoman's house', clearly does not apply to the more elaborate house

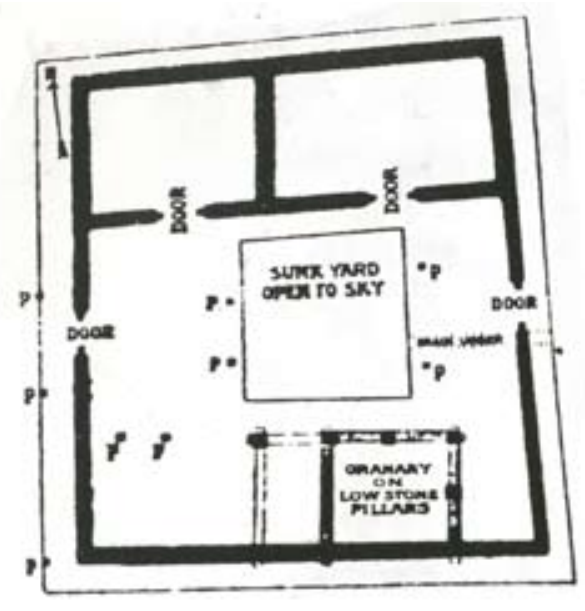

Figure 3:Coomaraswamy's generic Kandyan house form Source: Lewcock et al., 2002. forms of Kandyan elites. Squares and rectangles were the desired plan forms of these houses while the overall form was reduced to cuboids. They were always built on raised platforms termed "pila" above ground level. The outside area beyond and surrounding the Pila was referred to as "veli-midula" (sand or gravel court) and was always kept open free from vegetation; mostly paved by sand or gravel. This was done to prevent animals such as serpents entering the house from surrounding jungle.

The open interiors were demarcated by four blank walls with one or two doors placed at the opposite ends of the plan while windows found seldom use. The open spaces surrounding the central courtyard were generally austere, well-lit and airy. The living area was termed "Mahamaduwa" while the dining cum domestic space was given the name "Heenmaduwa" respectively (Perera, 1990:60). The rooms were always dark and gloomy in the absence of openings to outside. In Lewcock et al's (2002) view, the most important of these rooms was that used as a dark room for child birth. At other times it served to house the chests in which cloths were stored. Most importantly, rooms served as the sleeping quarters of women during the night when men always slept in Mahamaduwa. Within the internal space of the house, four or six stone pillars supported the "atuwa" or rice bins (large wooden chests). Occasionally the rice bins were separate structures outside the house in which case they were usually constructed, like the house, of a timber frame-work with in-filling walls of wattle-anddaub (Lewcock et al, 2002: 20). The size of these bins was a measure of the wealth of households and thus acted the role of a symbol of prosperity.

The building tradition utilized for these dwellings was a synthesis of grand and folk design traditions while the balance tilted more towards the latter. Folk tradition Vernacular was more explicit as all materials were obtained from the surrounding environment and hence, manifested a sense of environmental sustainability. The houses were crudely built and possessed simple wattle-and-daub (jungle timber frame filled with clay) walls while structural members of the usuallythatched roofs was of jungle timber. Straw was the main material of thatch in paddy-producing areas of the island (which included the hill country), and straw was laid on the timber frame work as either bundles or packed forms of approximately $200 \mathrm{~mm}$ thicknesses. Applying a new top layer was carried out, following every harvest. However, roofs of most of the surviving examples have later been covered with clay half round tiles. The particular type of local clay used for the wattle-and-daub construction is referred to in Sinhalese as "Makulu Mati", and gave walls a whitish finish once completed; as lime plastering and white washing with lime were prominent traits of Kandyan grand design tradition. Most of the surviving houses have also been possibly lime plastered and lime washed at later periods. Grand design tradition made 
rare appearances in these houses only in terms of the carpentry work. Door frames and sashes were mostly carved with traditional Sinhalese motifs while occasionally; ends of roof timber members (rafters) also manifested such adornment. Complicated door hinging and locking mechanisms are also a vital part of the Kandyan carpenter's repertoire.

Addressing of Kandyan dwellings of this generic type also known in Sinhalese as 'Hatara-andi-gedara' has always been a facile affair, where scholars in the field have continuously failed to conceive the major underlying difference between Kandyan elitism and sub-elitism, which could be manifested through their distinct domestic architectural practices. Hence, the above-addressed generic dwelling form could be directly attributed to the Kandyan sub-elite. When they rose to higher offices to become elites, they appropriated elite dwelling traditions. Hence, it could be avowed that, in such an austere milieu such as the Kandyan provinces, the domestic building perhaps, was the only means that the two stratums of the structure could make distinctive identities for themselves.

Only a handful of such sub-elite houses have survived the journey through time to the present-day in their purest and original forms, as most have been destroyed by haphazard-alterations or excessive post-independent period infrastructural development projects.
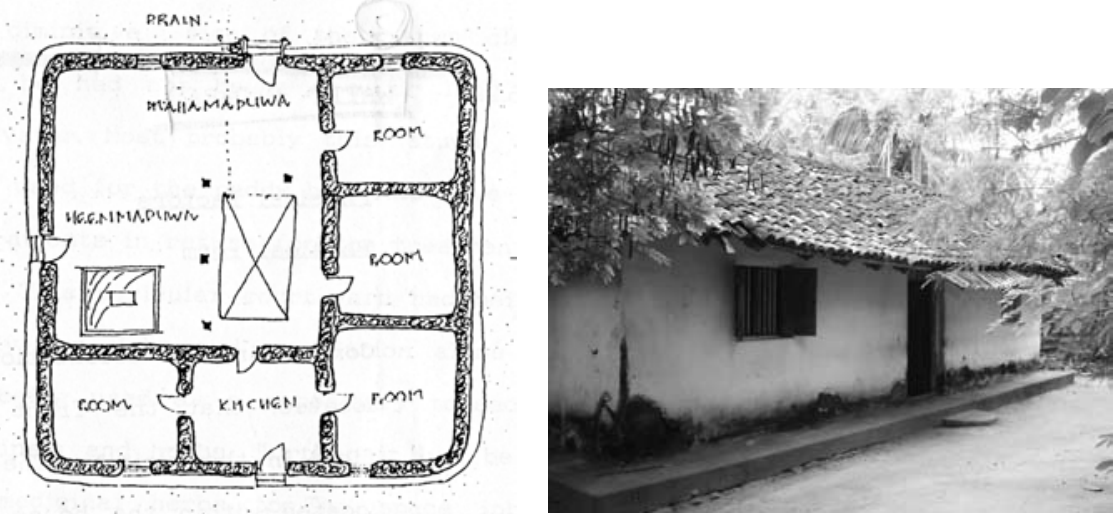

This best affirms the non-picturesque and façade-less nature of the austere Kandyan dwelling form.

\section{Extended versions}

The generic and simple form was occasionally amalgamated to form extended houses; prompted by the needs of extended families. The extensions could be carried out in any one of its four sides according to the situation in hand. At times, the extension was done with no court yard and light and ventilation was facilitated by doors and windows open to outside (Perera, 1990: 62). The roof extensions were also improvised according to the situation. It appears that there were no rules pertaining to these extensions. However, whether these extensions were carried out during the Kandyan period itself is ambiguous.

\section{Walauwe: manor houses of the elite}

The modifications to the generic dwelling form occurred, retaining its basic constituents, when the house belonged to someone of more political and economic influence; an elite. As Robert Knox

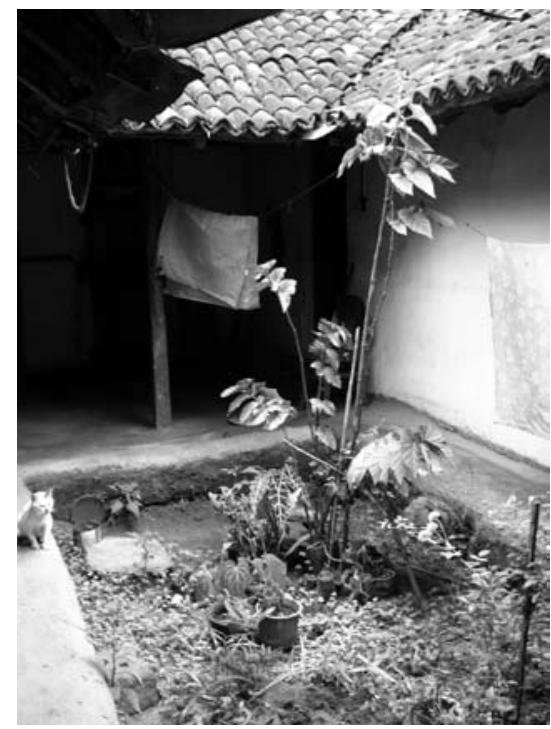

Figure 4: Hatara-andi-gedara at Matale called Wattegedara, belonging to a family line of petty officials or sub-elites; the last to occupy it being an Arachchi Mahattaya.

Source (the Plan): Perera, 1991.

As Pallasma (2005; 63) suggests, the experience of home is structures by distinct activities such as cooking, eating, socializing, reading, storing, sleeping, intimate acts etc., and not by visual elements. "A building is encountered; it is approached, confronted, related to one's body, moved through, utilised as a condition for other things. Architecture initiates, directs and organizes behavior and movement. A building is not an end in itself; it frames articulates, structures, gives significance, relates, separates and unites, facilitates and prohibits. Consequently, basic architectural experiences have a verb form rather than being nouns. Authentic architectural experiences consist then, for instance, of approaching or confronting a building, rather than formal apprehension of a façade...."
(Lewcock et al., 2002: 19) postulates, "The great people have handsome and commodious houses. They have commonly two buildings one opposite to the other, joint together on each side by a wall, which makes a square court-yard in the middle."

The beginning of this statement provides an ample idea about the bigger scale of elite houses in comparison, while the latter part explains an alternative way court yards were formed (rather than the common practice of forming a court yard by placing covered usable spaces around a central opening as in the examples studied), which is also affirmed by De Silva (1990, 2010). As Knox (in Lewcock et al., 2002: 19) further elaborates, "The houses of great persons only 

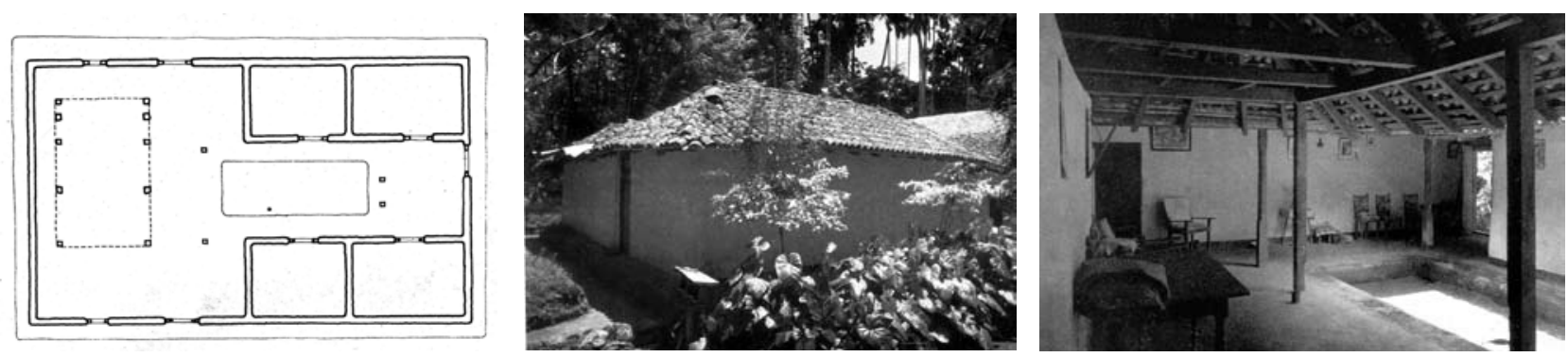

Figure 5: An extended sub-elite house from Manikdiwela near Kadugannawa in Kandy. The plan clearly illustrates the generic form and the new addition.

Source: Lewcocke, 2002

differed from those of lessen men by having more rooms and court-yards, better timber for the beamends, and verandah pillared, and their brackets well carved...."

The number of rooms was increased in these bigger houses while more courtyards were utilized to supply light and ventilation to the deep interiors. The arrangement was not always symmetrical and accommodated respective site situations. Out-houses were added to accommodate extended functions of the elite life style, which was not to be seen in the ones of the sub-elite to accommodate judgment halls (commonly seen in the houses of Disavas and Rate Mahattayas), larger kitchens, extra granaries (occasionally two storied), stables for horses, cattle sheds etc. According to De Silva (2010) elite houses illustrated the same materiality as the previously-addressed sub-elites counterparts, while some refinements were made under special privileges granted by the King; owing to outstanding services rendered to the Kingdom by such elites. Tiled roofs, lime plastered - lime washed walls, two-storey constructions and especially, refined carpentry work, which were traits of Kandyan grand design tradition evident in these edifices. As per Knox's (1966) affirmation, the roof structures were assembled with stronger and more valuable timbers. The members were always uniformly finished while beam ends and pillar brackets were carved with traditional Sinhalese motifs. The doors always had thick frames while both solid door and window sashes were elaborately carved. Iron-mongery was utilized commonly in fenestrations and was adorned with Sinhalese motifs. Even the function of building of such a Walauwe (manor house) itself had to be carried out with king's permission only as De Silva (2010) tells us, which affirms its status as the most ultimate symbolic manifestation of elitism in Kandyan society.

The most seminal observation which could be made about these houses is that the generic form which was earlier addressed, found repetitive use to arrive at more complex buildings. Hence, it could be rationally suggested that the number of times the repetition recurred was proportional to the prestige, wealth and thus, socio-political influence of the patron. This process of recurring repetition could also be attributed to nature, where such repetitions are explicit in its numerous structures. Hence, in a way, such dwellings were symbolic vestiges of the totality of Mother Nature. Moreover, all above postulations about such dwellings brings to the fore, the overarching influence on nature on physical forms. The austere lifestyles of inhabitants in direct contiguity to nature were facilitated through these forms. Houses were derived from nature and eventually returned to it, safeguarding its posterity. The built environments facilitated the entertaining of senses simultaneously and equally; not letting any single one dominate over others. "It is evident that the architecture of traditional cultures is also essentially connected with the tacit wisdom of the body, instead of being visually and conceptually dominated. Construction in traditional cultures is guided by the body in the same way that a bird shapes its nest by movements of its body. Indigenous clay and mud architecture in various parts of the world seem to be born of the muscular and haptic senses more than the eye" (Pallasmaa, 2005: 26).

Consequently, nothing ostentatious was allowed, making original Kandyan houses austere, but picturesque. The picturesque that predominantly caters to the eye, eventually found its way into Kandyan architecture via gradual Western influence the kingdom received. In his seminal examination of the historical using of senses, Pallasmaa $(2005 ; 25)$ affirms that, "The gradual growing hegemony of the eye seems to be parallel with the development of western ego-consciousness and the gradually increasing separation of the self and the world; vision separates us from the world whereas the other senses unite us with it".

He further elaborates that, "We can identify the transition of indigenous construction from the haptic realm into the control of vision as a loss of plasticity and intimacy, and of the sense of fusion characteristic in the setting of indigenous cultures" (Pallasmaa, 2005: 26). This in deed is evident in the modified sub-elite and elite houses of the Kandyan provinces.

After all,

"Western architectural theory since Leon Batista Alberti has been primarily engaged with questions of visual perception, harmony and proportion" (Pallasmaa, 2005: 26). 

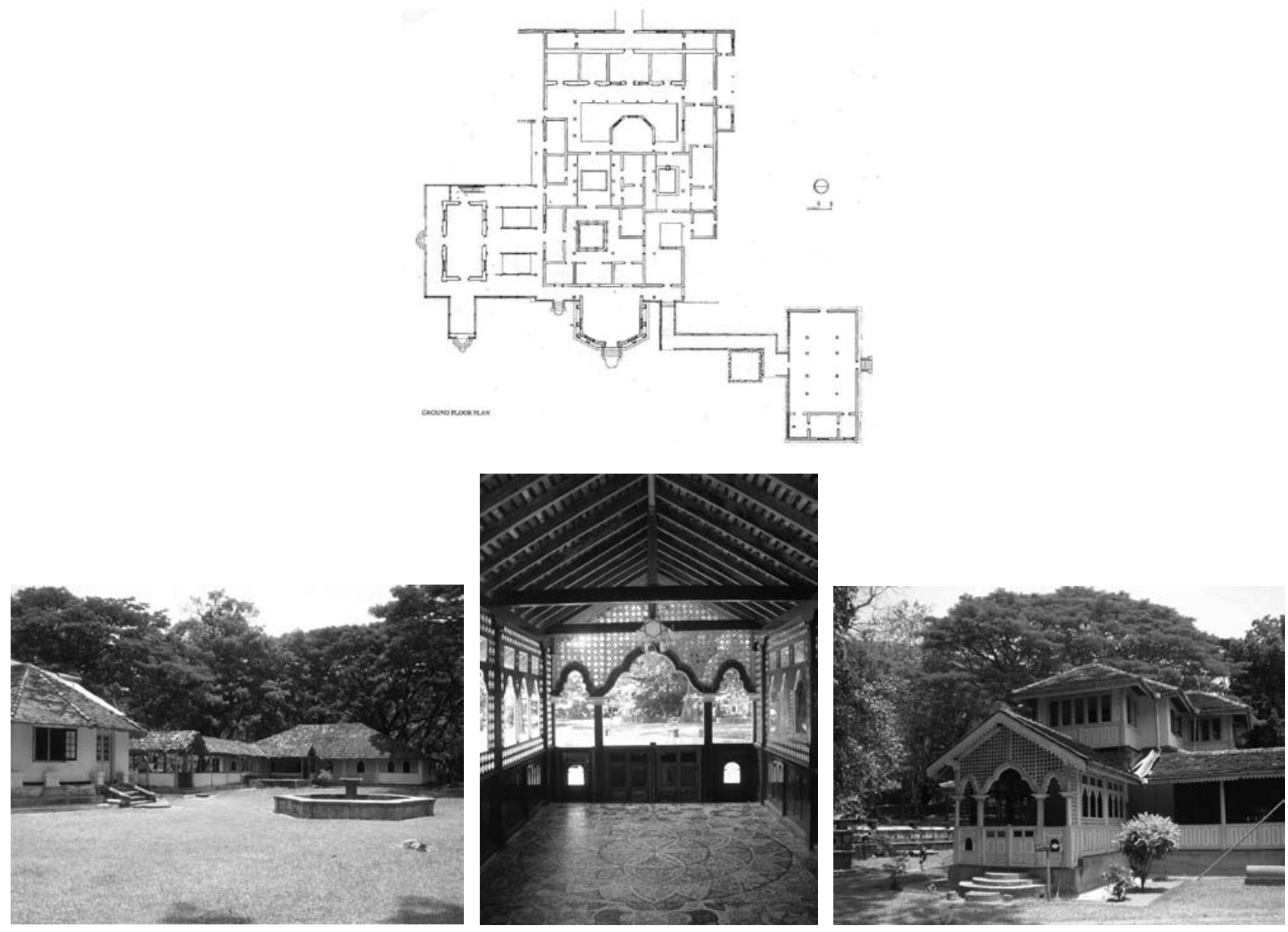

Figure 6 : Maduwanwela Walauwe

An elite Manor House at Ambilipitiya, was constructed in approx 1725 by Maduwanwala Maha Disave. This is one of the very few remaining manor houses which clearly manifest the repetitive use of the generic plan form, despite showing somewhat colonial influence in architectural features and detailing. Outward facing verandahs, multiple-use of courtyards, number of out-houses serving various functions (interconnected with covered walk ways) and one of the blocks consisting of two stories are its most conspicuous features. Certain modifications have been carried out to the manor house over the epochs. Some of the architectural features and detailing such as the decorated mosaic floors and intricate carpentry work (carved door window frames and sashes, trellis work, carved timber columns and roof members) are the most conspicuous colonial features.

Source (the Plan): Lewcock, 2002

The term 'walauwe' in Sinhalese carries the connotation for 'aristocratic dwelling' or 'manor house', was jealously-guarded during the Kandyan period. This not only connoted the dwellings of aristocrats, it was also used to identify the houses of high government officials who were classified under elite ranks earlier (who may or not be aristocrats). However, in certain parts of Kandyan regions according to De Silva (2010), even the houses of sub-elites (Koralas especially), later appropriated the term liberally.

\section{A Manifestation of Hybridity}

After the fall of Kandyan kingdom in 1815 (when it was ceded to the British colonial power), the term Walauwe's connotation became evermore prolific. Following the failed Kandyan independence struggle of 1818 led by Kandyan chiefs, the primordial privileges enjoyed by them (especially, the elite ranks) were abolished by the British, relegating them to an oblivious state. After the abolition of Rajakariya (land tenure system) by Colebrook commission in 1833, the Kandyan regions of Ceylon, just as the maritime, were gradually absorbed into the world capitalist mechanism of the British Empire, especially through the plantation industry soon to be introduced. This finally opened up the Kandyan regions to the onslaught of globalization at a time it was experiencing a quantum leap via industrialization and the culmination of European coIonialism. With the jettisoning of feudalism and land tenure system, the Kandyan social structure gradually collapsed and the gulf between elites, sub elites and masses was largely reduced. The most pertinent factor here was that, after 1833, the masses were given the franchise to engage in whatever profession they desired, irrespective of caste, and similarly, the laws that suppressed their building traditions were also lifted. The best example that could be adduced to illustrate this point is the sub-elite domestic rubric that 
came into existence parallel to these developments, commonly referred to as the "intermediate" type. The sub-elite dwellings grew in scale and size, while retaining the basic form of the generic version, and adopted certain elements from Dutch period domestic buildings and possibly, Phase-1 of British domestic counterparts, which were already well-received by the maritime populace of that time. Consequently, more rooms for more diversified functions (clearlydemarcated spaces for different functions) were accommodated in the planning of these dwellings with the gradual appropriation of certain Western cultural norms into Kandyan Sinhalese culture. Privacy, which has always been a conspicuous factor in the ego-centric modern Western culture finally penetrated Kandyan domestic form through the houses of their sub-elites in such a manner. Furthermore, material practices also began to change with the in- corporation of brick masonry for walls and columns which were plastered and white washed. Some architectural features such as round columns with square shaped bases and heads as well as masonry arches were also appropriated from hybrid maritime domestic versions along with carpentry details such as paneled door-window sashes and fluted roof timber members. The use of ironmongery also made an appearance for the first time in sub-elite dwellings. All such appropriated features best illustrate the liminality of the Kandyan sub-elite in a time of pioneering exposure of unprecedented nature, to Western globalization forces. It is noteworthy that only a faction of the Kandyan society of prior eras, who posed as elites, could enjoy such luxuries; analogous to pre-modern Western situations. However, the timelag between the two diverse realms is almost half a millennia.
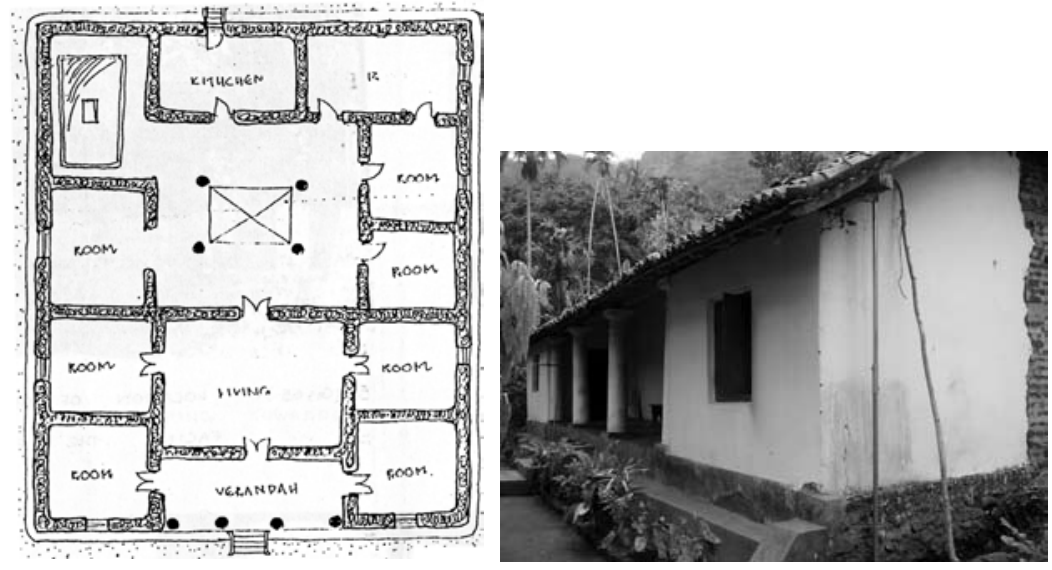

Figure 7: Atipola Walauwe

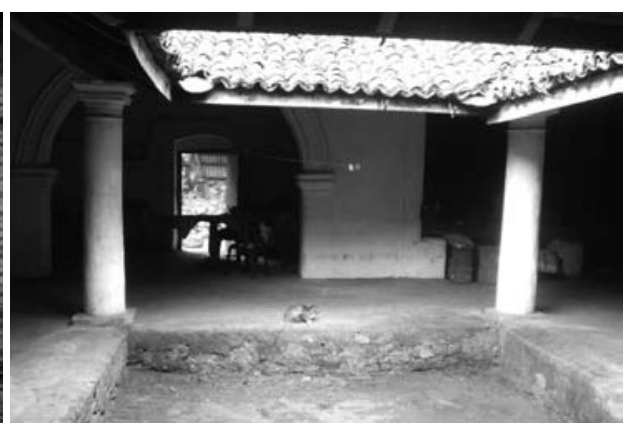

Built by a Korale Mahattaya, Atipola Walauwe is an "Intermediate type" house that belongs to a family line of petty Kandyan officials (sub-elite) from Matale. Note the term Wallauwe being used despite the owners being sub-elites. Although this somewhat resembles the generic plan form of a Hatara-andi-gedara, overt room divisions of interior as well as the increase in scale makes it distinctive. Owing to excessive use of fenestration all round the house, the internal courtyard lost its functional use, and was merely an attempt to continue a primordial building tradition. The most distinct feature is the masonry colonnaded front-facing verandah, which places it in contiguity with the parallel maritime colonial dwelling. These houses could be conceived as a synthesis of the Kandyan generic form and maritime colonial dwelling.

Source (the Plan) Perera, 1991

The acts of capitalism and consumerism spawned by the British-introduced plantation economy to the Kandyan regions by the mid 19th century lead to the fleeting proliferation of westernized house forms of local elites and sub-elites. Influences of Western colonial building traditions even affected bulk of the existing dwellings from the previous centuries, and altered their outlook beyond original recognition. Only a handful has survived and retained their original identity. Until this point in time, the laid-back cultural attitudes of the Sinhalese in general had been conceived by Westerners as mere "ignorance of comfortable living" (Cave,1894: 53).

Despite the overarching European colonial influence that subverts factional Sinhalese architectural trends, as in examples illustrated above, such dwell- ing forms were compatible with the ever-hybridizing lifestyles of the 19th Century Kandyan elites. These best-manifested the proliferating Western-hold, which was at the time, being concretized in the Kandyan provinces. In other words, what the Portuguese and Dutch achieved socio-culturally and architecturally in the maritime they ruled, had finally crept into Kandyan provinces. On the contrary, largely-unaffected by such Western forces, the proletarian rural masses kept on living in their primitive vernacular forms, well into the neo-liberal economic reforms that the independent nation state of Sri Lanka underwent in 1977 (Jayawardene.1984: 92)

Menin and Samuel (2003) in their phenomenological exploration of the works of Le Corbusier and Alvar Alto (considered to be two of the most prominent 

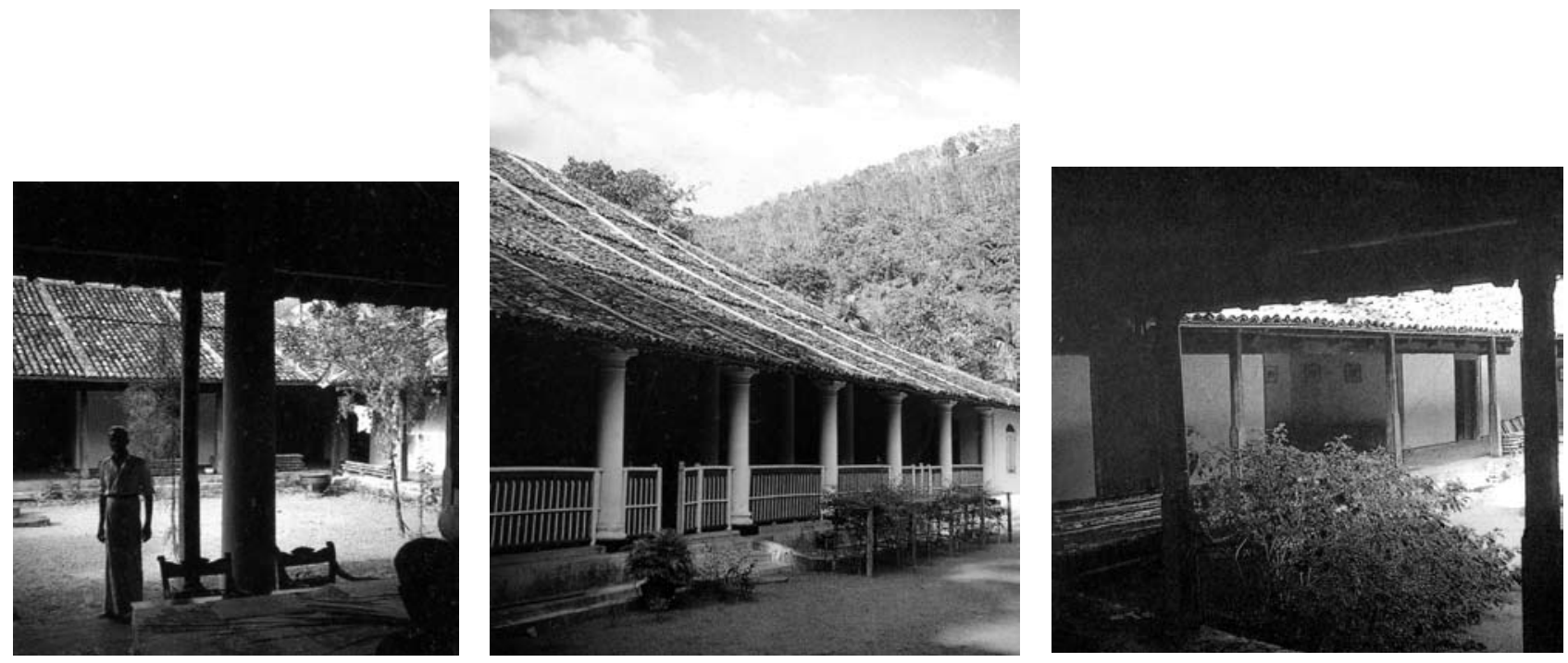

Figure 8 : Ekneligoda Walauwe

An elite Manor House at Ekneligoda in Rathnapura. Originally built in the 18th Ct., the house of Ekneligoda Disawe, has undergone extensive modifications during the 19th century British colonial period. This house is the ideal example for the Kandyan elite appropriation of the Maritime elite domestic model. The plan form illustrates typical characteristics of a Dutch colonial dwelling than a traditional manor house, the most unique features being the front double verandah, the rear and side verandahs. However, the prominence given to the court yard is noteworthy. Architectural features such as masonry colonnades illustrate strong colonial Dutch influence. Furthermore, door-window detailing as well as the carpentry work (such as paneled door and glazed window sashes, glazed half-round fanlight arches over fenestrations, rear and side verandah columns, verandah fences around the house, rear storage attics) also places the building in contiguity to its maritime counterparts from the same period.

Source: Lewcock, 2002

figures of 20th century European-instigated rubric of Modern architecture), reveal the underlying inspirations of nature in their works. The sterile architecture of historicism and capitalist pretension in the previous centuries prompted them to inveigle their respective approaches (which appear to be dissimilar from the surface, but possess the same underlying grounds) to be more humanistic, closely-associated with the patterns and forces of mother nature. Hence, this was an attempt to unite the human spirit with nature; the place where it all began. The repetitive patterns and accommodating trends of nature are thus, explicit in their affluent portfolios of work. It could be logically conceived that these very trends were overtly apparent in the austere Kandyan elite and sub-elite dwellings (the original ones), centuries before them.

\section{Conclusion}

The Western-derived structural distinction between 'elite' and 'sub-elite' could be applied to the medieval Kandyan situation, and Kandyan elite and sub-elite dwellings respectively, could be adduced as the most apposite examples to overtly manifest the two unique conditions.

The politically and socially influential positions of highest caliber identified by this paper in the Kandyan administrative hierarchy could be conceived as the ones of Kandyan elites. As an unrivalled and homogeneous political entity, this rather small group could be further identified as the 'governing elite' in the absence of a 'political class'. The more numerous and less influential lower administrative positions 
discussed in the paper, thus become the Kandyan sub-elite. The generic house form termed the 'Hataraandi-ge' was therefore, delimited to the sub-elite while the elite Walauwe was a repetition of this basic block. The recurrence of the basic block was proportional to the political and social influence of the patron. The former domestic type mainly utilized vernacular tradition in its making while employing vestiges of grand design tradition. The latter in comparison, used the same equation although tilting more towards grand design tradition. Even the term Walauwe was a jealously guarded affair. Hatara-andi-ge was an articulation of a Sinhalese culture that imbued Theravada Buddhist teachings, while Walauwe was a hybrid cultural manifestation between Buddhism and Hinduism. However, the boundary between Kandyan elite and sub-elite dwelling was blurred after 1796, as the maritime colonial influence of modernity crept into the Kandyan provinces. Thus, the Western forces of globalization gradually took hold and altered these house forms beyond original recognition via European-introduced cultural and thus architectural practices.

On the other hand, what underlie Eastern and Western elitisms could be conceived as binary oppositions. Eastern elitism sprung up in cultures, analogous in many ways to the medieval Kandyan condition. With the influences of Eastern religions such as Hinduism and Buddhism (in this case), co-existence with the environment was always exalted. Henceforth, the resultant socio-political structures were both repressive and unproductive in the Western sense. With laws clearly demarcating and concretizing the immutabilities of elite and sub-elite stratums that enjoyed limited privileges, a potential for the contingent to proliferate in numbers was jettisoned. Most prominently, the fact that the environment would not be subverted but sustained was ensured. Western culture, conversely, inveigled from such shackles from the 15th century, and instigated an ego-centric modernity and thus the modern-era, that has recurrently dwelled on exploitative capitalism. Capitalist practices have not only redefined Western elitism via lifting of religious and thus cultural barriers, it has furthermore dictated terms for elitism and sub-elitism in the subordinate world. Consequently, elitism and sub-elitism were constructed as attainable stratums for the masses. The overall result of this process has lead to gradual exploitation and thus, destruction of the natural environment, which has reached catastrophic levels by contemporary times. On the other hand, as the direct result of the race to attain such ambitions, human conflicts exacerbated, and have reached an unprecedented climax by today. Moreover, all such processes have now backfired on the capitalist system itself, making one question of it future continuity.

Although the medieval Kandyan social structure is commonly-perceived to be one governed by repressive cultural rules and norms, its relative level of free- dom could be affirmed analogous with the situation of pre-modern Europe. Hence, the sense of austerity evident in Eastern cultures, which is articulated via its vernacular-driven architecture (despite being considered primitive in the Western sense), possess great sensitivity to nature and to humanity in the long run. However, such conditions are no longer in existence, owing to their replacement by precarious westernled capitalist forces of the modern era that infiltrated these cultures via colonialism. The intermediate type Kandyan dwelling of the sub-elite along with the modified elite manor house hence, become ideal models to manifest the succumbing of a once-solitary Eastern society to a capitalist and globalized system. Furthermore, they also manifest the state of hybridity of a colonized population.

The pre-modern Kandyan generic house form conversely, articulates not only its contiguity to nature, but also phenomenological affinity as underlying factors. Catering to the picturesque that is based on the modern-era trends of retinal imagery and Cartesian idealism is neglected here.

\section{References}

Barber, B. (1968) Mobility in Hindu India: Social Mobil ity in the caste system in India, Bom bay: Silverberg.

Bottomore, T. B. (1993) Elite and Society, 2nd edi tion, London: Routledge.

Cave, H. W. (1894) Picturesque Ceylon: Kandy and Peradeniya, Marston: Sampson Low.

Cave, H. W. (1908) The Book of Ceylon, London: Cassell.

Coomaraswamy, A. K. (1956) Medieval Sinhalese Art, New York: Pantheon Books Ltd.

Cordiner, J. (1807) A Description of Ceylon, London: Logman Hurst.

Davy, J. (1969) An Account of the Interior of Ceylon and of its Inhabitants with Travels in that Is land, Colombo: Tisara Prakasakayo.

De Silva, K. M. (1981) A History of Sri Lanka, Berke ley and Los Angeles: University of California Press.

De Silva, N. (2006) [Environment and Western Con cepts], Chinthana Parshadhaya: Maha ragama.. (In Sinhalese).

De Silva, N. (March 2003) Jathiye Iranama,[Online], Available: http://www.kalaya.org/audio7.html [26 May 2010].

De Silva, N. (6th November 2008) Pandu Aba saha Jathiye Vikashaya, [Online], Available: http://www.kalaya.org/audio10.html [26 May 2010].

De Silva, T. K. N. P. 2010 [Interview Comments] August 3.

De Silva, T. K. N. P. (1990) 'The Sri Lankan Tradi tion for Shelter', The Journal of Sri Lanka Institute of Architects, Vol 10, No 6. 
Evans, R. (2003) Translations from Drawing to Build ing and Other Essays, Janet Evans and $\mathrm{Ar}$ chitectural Association Publications: London.

Horton, P. (1964) Sociology, Western Michigan Uni versity: Michigan.

Jayawardene, S. (1984) 'The Work of Geoffrey Bawa: Some Observations Towards a Histori cal Standing, M.Sc. Dissertation, University College London.

Jose, J. (1998) Biopolitics of the Subject: An Intro duction to the Ideas of Michael Foucault, Northern Territory University Press: Darwin.

Knox, R. (1966) A Historical Relation of Ceylon, Ti sara Prakasakayo: Colombo.

Lewcock, R. Sansoni, B. and Senanayake (2002) The Architecture of an Island: The Living Heritage of Sri Lanka, Barefoot (Pvt.) Ltd: Colombo.

Madugalle, S. J. (2005) Four Kandyan Families: From the Maha Disawani of Matale, Dumbara and Uva, Vijitha Yapa Publi cations: Colombo.

Mandel, E. (1982) Introduction to Marxism, Pluto Pres Ltd: London.

Menin, S. and Samuel, F. (2003) Nature and Space: Alto and Le Corbusier, Routledge: London.

Mills, L. A. (1964) Ceylon under British Rule 17951932, Oxford University Press: London.

Mosca, G. (1939) The Ruling Class, McGraw-Hill: New York.

Pakeman, S. A. (1970) Ceylon between Orient and Occident: Zeylanicus, Elek Books Limited: London.

Pallasmaa, J.(2005) The Eyes of the Skin: Architec ture and the Senses, Wiley-academy: Sussex.

Pareto, V. (1963) A Treatise on General Sociology 1915-19, Dover: New York.

Perera, A. (1991) 'Court Yard Concept in Sri Lanka with Special Reference to Traditional Dwell ings in the Central Province: Matale', B.Sc. Dissertation, University of Moratuwa.

Perera, M. C. N. (1994) 'Decolonizing Ceylon: Soci ety and Space in Sri Lanka', PhD Thesis, State University of New York at Binghamton.

Rapoport A. (1969) House Form and Culture, Pren tice-Hall, Inc: New Jersey.

Roberts. M. (1995) Cast Conflict and Elite Forma tion:The Rise of a Karava Elite in Sri Lanka 1500-1931, Navarang (in collaboration with Lake House Bookshop): New Delhi.

Said, E. W. (2003) Orientalism, Penguin Books Ltd: London.

Shumpeter, J. A. (1942) Capitalism, Socialism and Democracy, Routledge: London.

Steger, M. B. (2003) Globalization: A Very Short Introduction, Oxford University Press: Oxford.

\section{End Notes}

${ }^{1}$ Furthermore, the earliest known usage of the term 'elite' in the English language could be traced back to the Oxford English Dictionary of 1823 , at which time it was already applied to various social groups, establishing the above elucidation.

2 Moreover, Horton provides his valuable opinion regarding the power dimension associated with elitism, as well as their volume in society.

${ }^{3}$ This class undergoes changes in its membership over a period of time, ordinarily by the recruitment of new individual members from the lower strata of society, sometimes by the incorporation of new social groups. Occasionally these rather-established elite are replaced completely by a 'counter elite', in situations such as revolutions, in a process referred to as the 'circulation of elites'.

${ }^{4}$ The treaty was to pledge the support of the Dutch to Kingdom of Kandy to overthrow the Portuguese and in return a number of important ports around the country will be opened up to the Dutch for their trading activities. It further explained that the Singhalese king should be regarded and respected as the supreme ruler of the island by the Dutch while they should hand over all the other ports and regions acquired by them from the previous colonizer. The intention behind the granting a number of sea-ports to the Dutch was to let them recover their expenses incurred at the war against the Portuguese and allow them get established in the trade-scene of the country.

${ }^{5}$ During this crucial period, just prior to the British arrival Dutch had blockaded Kandy and secured more territory including all its sea ports and trading privileges. They were determined to reap as much harvest from the lucrative cinnamon trade and other cultivations of pepper, coffee and spices, not to mention the profitable trade of elephants.

6 "A related case is of more ominous significance. Consider the emergence of the feudal type of landlordism in the kingdom of the Franks during the sixth and seventh centuries. This was certainly a most important event that shaped the structure of society for many ages and also influenced conditions of production, wants and technology included. But its simplest explanation is to be found in the function of military leadership previously filled by the families and individuals who (retaining the function however) became feudal landlords after the definitive conquest of the new territory.": This is in deed what took place in the Lankan frontier, when Indians migrated from Northern parts of India two and a half millennia ago.

7 It has to be noted here that even the cultivator (Govigama) cast itself, has other sub casts within it such as Bathgama etc.

8 In the field of world-architecture, Amos Rapoport identifies the difference between the 'grand design tradition' and 'folk tradition' based on other similar scholarly classifications. He claims that the monument-buildings belong to the grand design tradition and are built to impress either the populace with the power of the patron, or the peer group of designers and cognoscenti with the cleverness of the designer and good taste of the patron (Rapoport, 1969: 2).

${ }^{9}$ A number of British missions visited Kingdom of Kandy both before and after their conquest of the coastal areas ruled by the Dutch in 1796. The intentions behind these visits were the fact that British wanted to arrange some form of a treaty with the Singhalese king, although this never became a reality. Referring to reports and descriptions by some of these foreigners to visit Kandy is the best way of understanding of what Kandyan elite domestic architecture was like at the time (Mills, 1964: 1-7). 